\title{
Synthesis of $\mathrm{SnO} 2$ and $\mathrm{Zn}$ doped $\mathrm{SnO} 2$ Nanoparticles by Flame Oxidation Process for Photocatalytic degradation of Methylene Blue Dye
}

SIVARAMA PRABHU P

P.A.College of Engineering and Technology https://orcid.org/0000-0002-3366-7915

KATHIRVEL PONNUSAMY ( $\sim$ ponkathirvel@gmail.com )

P.A.College of Engineering and Technology

D Maruthamani

PSG College of Technology, Coimbatore

S.D Gopal Ram

PSG College of Technology, Coimbatore

\section{Research Article}

Keywords: Tin oxide, Zinc doped Tin oxide, flame synthesis, Methylene Blue, photocatalyst

Posted Date: September 29th, 2021

DOI: https://doi.org/10.21203/rs.3.rs-935602/v1

License: (c) (i) This work is licensed under a Creative Commons Attribution 4.0 International License. Read Full License 


\title{
Synthesis of $\mathrm{SnO}_{2}$ and $\mathrm{Zn}$ doped $\mathrm{SnO}_{2}$ Nanoparticles by Flame Oxidation Process for Photocatalytic degradation of Methylene Blue Dye
}

\author{
P. Sivarama Prabhu ${ }^{1,2}$, P. Kathirvel ${ }^{1 *}$, D. Maruthamani ${ }^{3}$, S.D. Gopal Ram ${ }^{4}$ \\ ${ }^{1}$ GRD Centre for Materials Research, Department of Physics, PSG College of Technology, Coimbatore, Tamil \\ Nadu, India-641004. \\ ${ }^{2}$ Department of Physics, P.A. College of Engineering \& Technology, Pollachi, Tamil Nadu, India-642002. \\ ${ }^{3}$ Department of Chemistry, PSG College of Technology, Coimbatore, Tamil Nadu, India-641004. \\ ${ }^{4}$ Department of Physics, PSG College of Technology, Coimbatore, Tamil Nadu, India-641004.
}

*Corresponding author Email address: ponkathirvel@ gmail.com

\begin{abstract}
A very simple and rapid flame oxidation method is effectively used to synthesis pure Tin Oxide $\left(\mathrm{SnO}_{2}\right)$ and $\mathrm{Zinc}$ doped Tin Oxide $\left(\mathrm{Zn}: \mathrm{SnO}_{2}\right)$ nanoparticles from the metallic Tin $(\mathrm{Sn})$ and Zinc (Zn) powders for the photocatalytic degradation of Methylene blue (MB) dye and characterized to study their structural, optical, elemental and chemical properties. From the $\mathrm{X}$-ray diffraction analysis (XRD) it indicates that the synthesized $\mathrm{SnO}_{2}$ and $\mathrm{Zn}: \mathrm{SnO}_{2}$ nanoparticles have pure tetragonal and cubical phases respectively and their average size increases when $\mathrm{Zn}$ was doped with $\mathrm{SnO}_{2}$. Raman spectral studies confirms the various mode of vibrations and the crystal structure of the synthesized nanoparticles from the spectral peaks of Raman shifts. Purity, atomic percentage and chemical composition were analysed using Energy dispersive X-ray analysis (EDX). The band gap energy was increasing from $3.5 \mathrm{eV}$ to $3.6 \mathrm{eV}$ when doping of $\mathrm{Zn}$ with $\mathrm{SnO}_{2}$, which was revealed from the UV-visible spectroscopic analysis. Photoluminescence analysis (PL) confirms the red shifted emission for $\mathrm{Zn}: \mathrm{SnO}_{2}$ due to the oxygen deficiency. The CIE chromaticity $(\mathrm{x}, \mathrm{y})$ for $\mathrm{SnO}_{2}$ and $\mathrm{Zn}: \mathrm{SnO}_{2}$ was calculated from the emission spectra and the cordinates represents blue and violet region respectively. Field Emission Scanning Electron Microscopy (FESEM) analysis shows that the pure $\mathrm{SnO}_{2}$ nanoparticles have irregular, agglomerated, nanoflowered and nanoclustered formation whereas $\mathrm{Zn}: \mathrm{SnO}_{2}$ nanoparticles have more crystalline, cubical and nanoflakes structures. The photocatalytic activity was enhanced due to the presence of $\mathrm{Zn}$ in $\mathrm{SnO}_{2}$ under UV light irradiation. The efficiency of $\mathrm{MB}$ degradation by $\mathrm{SnO}_{2}$ and $\mathrm{Zn}: \mathrm{SnO}_{2}$ nanoparticles are above $80 \%$, which proves to be an effective photocatalyst.
\end{abstract}

Keywords: Tin oxide, Zinc doped Tin oxide, flame synthesis, Methylene Blue, photocatalyst

\section{Introduction}

In the daytoday life, every countries economy depends upon the goods and products that have been manufactured from the industries. Although industrial development offers many advantages to society, but also few disadvantages are there with the environmental industries [1]. Mainly, industrial effluent reflects its impact on human life due to its presence in the ecosystem. Generally, most industries produce effluents while producing products, among which the textile industry is the one that generates dyes [2]. Dyes are one of the main pollutants that create environmental risks for all the living organisms in the earth. As these 
dyes have complex structure makes them more stable and the removal or degradation of these complex molecules from effluents are very difficult. Recent research has focused on the elimination of toxic organic pollutants in wastewater by physical, chemical and biological process but these processes have certain limitations [3].

It is recognized that the photocatalyst is an effective method for wastewater treatment that includes organic contaminants. In photocatalytic degrading process, the nanoparticles catalytic abilities are enhanced due to the presence of ultraviolet radiation, which acts like an stimulator for light induced redox reactions [4]. Owing to the presence of nanoparticles as photocatalyst, degradation of organic dyes has improved, because of this, there is a urge for new techniques to produce several nanomaterials with the required chemical, physical and electronic properties [5]. Among these, metal oxide semiconductor nanoparticles having large band gap were recently explored to a large extent due to their surprising variations in their properties when they are reduced to small size because of quantum size effect or quantum confinement [6]. Metal oxide nanoparticles have been synthesized for different applications, amidst them $\mathrm{SnO}_{2}$ one of the most significant, wide band gap (3.6 eV) [7], n-type semiconductor was examined for applications like gas sensors, LED, Solarcells, photocatalysts, spintronic devices, optoelectronic devices, supercapacitors and Lithium Ion batteries [8-20]. $\mathrm{SnO}_{2}$ an inorganic compound having large exciton binding energy of 130 $\mathrm{meV}$, was selected abundantly due to their ability of doping with many dopants like Iron, Graphene, Manganese, Antimony, Iodine, Copper, Zinc, Indium, Silicon and Fluorine [9-30]. When $\mathrm{SnO}_{2}$ was doped with any of these dopants its properties like optical, structural, chemical compositional, magnetic behaviour, photovoltaic properties, gas sensing abilities, electrical properties, electrochemical properties, etc., where changed to a large extent due to the presence of large oxygen deficiency [6-31]. Among these dopants Zn, a d-group element in the periodic table shows enhanced crystallite structures, optical, electrical and magnetic properties [22].

Many methods have been reported for the synthesis of $\mathrm{SnO}_{2}$ nanostructures like hydrothermal, sol-gel, low temperature solution process, chemical precipitation, coprecipitation, chemical digestion method, microwave irradiation method, spray combustion, electrospinning, magneton co-sputtering, laser pyrolysis, gas phase technique and chemical spray pyrolysis [6-32] but most of these methods employed hazardous chemicals, took longer time to react and involve sophisticated instruments. Synthesis of $\mathrm{SnO}_{2}$ and $\mathrm{Zn}$ doped $\mathrm{SnO}_{2}$ nanoparticles by flame oxidation or flame synthesis method proves to be very significant, low cost, high purity, high quantity, single step process producing materials in nanodimension[6,8]. The majority of textile industries use azo based acidic dyes for binding dyes on fabrics, methylene blue(MB) a cationic dye used abundantly for textile industrial purposes [4].

In the present research work, we report, the photodegradation of model effluent $\mathrm{MB}$ dye in the presence of pure $\mathrm{SnO}_{2}$ and $\mathrm{Zn}: \mathrm{SnO}_{2}$ nanparticles as photocatalysts under uv irradiation and their characterization.

\section{Materials and methods}

\subsection{Synthesis of pure $\mathrm{SnO}_{2}$ and $\mathrm{Zn}: \mathrm{SnO}_{2}$ nanoparticles}

The schematic diagram of the flame synthesis method is shown in fig.1. In this method, both the oxygen and acetylene gases are mixed in equal proportion $\left(50 \mathrm{O}_{2}: 50 \mathrm{C}_{2} \mathrm{H}_{2}\right)$ and send through the nozzle from the oxygen and acetylene cylinders. Using regulator the flow of gases through the nozzle can be regulated to get bluish flame. A powder feeder with a stopper was used to supply the powders into the flame. A powder collector was placed over the reaction 
chamber about $25 \mathrm{~cm}$ from the nozzle to collect the deposited nanopowders. Metallic Sn powders of about $40 \mu \mathrm{m}$ was filled in the powder feeder and directed towards the bluish flame under gravitation and the uniformity of the powder flow was regulated by the stopper. The metallic Sn powders gets melted in the high temperature flame and gets oxidised directly to form $\mathrm{SnO}_{2}$ nanoparticles and are deposited over the powder collector [6,8].

Similarly, both the metallic Sn and Zn micro powders mixed in the ratio of $40 \mathrm{~g}: 10 \mathrm{~g}$ are filled in the powder feeder and fed into the oxy-acetylene bluish flame under gravitational force. Both these metallic powders gets melted in the flame and oxidised to form $\mathrm{Zn}: \mathrm{SnO}_{2}$ nanoparticles. Then both the deposited pure $\mathrm{SnO}_{2}$ and $\mathrm{Zn}: \mathrm{SnO}_{2}$ nanoparticles were collected from the powder collector and characterized for further studies [8].

\subsection{Photocatalytic degradation experiment}

The photocatalytic degradation activity of pure $\mathrm{SnO}_{2}$ and $\mathrm{Zn}: \mathrm{SnO}_{2}$ nanoparticles as catalysts on Methylene blue (MB) irradiated under UV radiation were evaluated by the decolorization of $\mathrm{MB}$ aqueous solution [2]. A $125 \mathrm{~mW} / \mathrm{cm}^{2}$ (40 W) UV lamp was used as the uv light source to induce the photocatalytic process. $10 \mathrm{mg}$ of $\mathrm{SnO}_{2}$ and $\mathrm{Zn}: \mathrm{SnO}_{2}$ nanoparticles were magnetically stirred with $50 \mathrm{ml}$ of aqueous $\mathrm{MB}$ solution to obtain uniform dispersion and placed under dark for 2 hours to achieve adsorption-desorption equilibrium. The reaction mixture containing both the photocatalysts and MB dye were irradiated with the uv light for $(30,60,90,120,150$ and $180 \mathrm{~min})$ regular intervals of time and the sample was tested by UV-visible spectrophotometer to measure the steady state absorption. The photocatalytic degradation efficiency(E) of $\mathrm{MB}$ was calculated by,

$$
\mathrm{E} \%=\left[\left(1-\mathrm{C}_{\mathrm{t}} / \mathrm{C}_{\mathrm{o}}\right)\right] \times 100 \%
$$

Where $\mathrm{C}_{\mathrm{t}}$ is the concentration of MB solution with the photocatalysts (after irradiation of UV light for ' $\mathrm{t}$ ' time interval) and $\mathrm{C}_{\mathrm{o}}$ is the concentration of $\mathrm{MB}$ solution without catalysts [16].

\section{Results and Discussion}

Pure $\mathrm{SnO}_{2}$ and $\mathrm{Zn}: \mathrm{SnO}_{2}$ nanoparticles synthesized via direct oxidation of the flames were characterized by XRD, Raman spectroscopy, EDX, UV visible spectroscopy, Photoluminescence and FESEM. X- ray Diffraction (XRD) was done to analyse their structural properties like particle size, crystalline nature and phases present in the synthesized nanoparticles [19]. Raman spectroscopy was used to confirm the Raman active vibrational modes of the synthesized nanoparticles within the range of $50-900 \mathrm{~cm}^{-1}$ [25]. Chemical composition and purity of $\mathrm{SnO}_{2}$ and $\mathrm{Zn}: \mathrm{SnO}_{2}$ nanoparticles was confirmed by Energy Dispersive X-ray Analysis (EDX) [19]. UV visible spectrophotometer (JASCO V-770) in the measurement range of $200-900 \mathrm{~nm}$ was used to study their optical properties. Using PL spectrometer FP-8300, photoluminescence (PL) studies of both the synthesized nanoparticles was done at the excitation wavelengths of $340 \mathrm{~nm}$ and $410 \mathrm{~nm}$ to check the presence of any defects or vacancies [24]. Both the synthesized nanoparticles were examined by FESEM to verify the crystal structure and surface texture [6].

\subsection{Structural analysis}

XRD is one of the most vital characterization method to identify the average crystallite sizes, structure and phases present in the synthesized nanoparticles. Fig.2 shows the xrd pattern of pure $\mathrm{SnO}_{2}$ and $\mathrm{Zn}: \mathrm{SnO}_{2}$ nanoparticles by the very simple and rapid flame oxidation method. From the fig.2, it confirms that the $\mathrm{SnO}_{2}$ nanoparticles have tetragonal phase and the planes 
(110), (101), (200), (111), (211), (220), (002), (301), (112), (301), (202) and (321) matches with the tetragonal structured $\mathrm{SnO}_{2}$ (JCPDS card No. 00-041-1445, space group: P42/mnm, group number:136) [25]. From the xrd pattern of $\mathrm{Zn}: \mathrm{SnO}_{2}$ nanoparticles, there exists peaks representing the planes (111), (220), (311), (222), (400), (422), (511), (440), (531), (620), (533) and (711) which matches with the cubical phased $\mathrm{Zn}: \mathrm{SnO}_{2}$ (JCPDS card No. 00-0241470, space group:Fd-3m, group number:227). From the xrd pattern it was observed that because of the $\mathrm{Zn}$ dopant in $\mathrm{SnO}_{2}$ the intensity of the peaks were decreased considerably which indicates the clear bonding of $\mathrm{Zn}$ in the $\mathrm{SnO}_{2}$ lattice [19].

The average crystallite size was calculated for both the $\mathrm{SnO}_{2}$ and $\mathrm{Zn}: \mathrm{SnO}_{2}$ nanoparticles and found to be $29 \mathrm{~nm}$ and $30 \mathrm{~nm}$ respectively. Debye-Scherrer formula was used to calculate the crystallite size,

$$
\mathrm{D}=\mathrm{K} \lambda / \beta \cos \theta
$$

Where, $\mathrm{K}$ is a constant $(0.9), \lambda$ is the $\mathrm{Cu}-\mathrm{K} \alpha(1.5418 \AA) \mathrm{X}$-ray wavelength, $\theta$ is the Diffracted angle in radians and $\beta$ is the FWHM intensity in radians [22,33]. Increase in the average particle size confirms the doping of $\mathrm{Zn}$ in the $\mathrm{SnO}_{2}$ lattice, when the $\mathrm{Zn}$ is doped some of the $\mathrm{Sn}$ ions may be replaced or $\mathrm{Zn}$ occupies the intermediate position between $\mathrm{Sn}$ and $\mathrm{O}$. Microstrain $(\varepsilon)$ is determined for both $\mathrm{SnO}_{2}$ and $\mathrm{Zn}: \mathrm{SnO}_{2}$ from the formula,

$$
\varepsilon=\beta \cos \theta / 4
$$

From the microstructural strain values it indicates the lattice defects due to the doping of $\mathrm{Zn}$. Microstrain values remains constant even after the doping of $\mathrm{Sn}$ indicates the substitution of Sn ions by $\mathrm{Zn}$ ions in the crystal lattice [33]. Lattice constants are found as $\mathrm{a}=4.74 \AA$ and $\mathrm{c}=3.19 \AA$ for $\mathrm{SnO}_{2}$ and as $\mathrm{a}=8.66 \AA$ for $\mathrm{Zn}: \mathrm{SnO}_{2}$. Lattice constant values are calculated using the formula,

$$
\frac{1}{d^{2}}=\frac{\left(h^{2}+k^{2}\right)}{a^{2}}+\frac{l^{2}}{c^{2}}
$$

The change in lattice constant value was due to the addition of $\mathrm{Zn}$ in the $\mathrm{SnO}_{2}$ lattice which changes the tetragonal phased $\mathrm{SnO}_{2}$ to Cubical phased $\mathrm{Zn}: \mathrm{SnO}_{2}[19,33]$.

\subsection{Raman spectroscopic analysis}

Raman spectroscopy is used to investigate the structural defects like stacking faults, oxygen vacancies, crystallinity and the size effects of nanoparticles [25]. There exists 18 vibrational modes from six unit cell atoms of $\mathrm{SnO}_{2}$, which are symbolized by $\Gamma=A_{1 g}+A_{2 g}+B_{1 g}+B_{2 g}+E_{g}+2 A_{2 u}+2 B_{1 u}+4 E_{u}$. Among these, Raman active modes are $B_{1 g}, B_{2 g}$, $A_{1 g}$ and $E_{g}$ while $E_{u}$ and $A_{2 u}$ corresponding to infrared active region. Acoustic modes are one $A_{2 u}$ and two $E_{u}[16,20]$ while $A_{2 g}$ and $B_{1 u}$ represents silent mode. Fig.3 shows the Raman spectra of pure $\mathrm{SnO}_{2}$ and $\mathrm{Zn}: \mathrm{SnO}_{2}$ nanoparticles at room temperature. In the Raman active

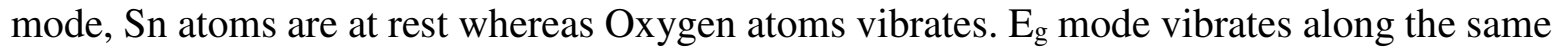
directions whereas $A_{1 g}, B_{1 g}$, and $B_{2 g}$ vibration modes vibrates at $90^{\circ}$ to the c- axis. Out of these non-degenerate modes of vibrations, $\mathrm{B}_{1 \mathrm{~g}}$ mode vibration around the $\mathrm{c}$-axis was due to the rotation of six octahedral oxygen atoms [16].

From fig.3, Raman spectrum peaks at 631,678 and $696 \mathrm{~cm}^{-1}$ matches to the asymmetric stretching of $\mathrm{SnO}_{2}\left(\mathrm{~A}_{1 \mathrm{~g}}, \mathrm{~A}_{2 \mathrm{u}}\right.$ and $\mathrm{B}_{2 \mathrm{~g}}$ modes), which confirms the tetragonal crystal structure of synthesized $\mathrm{SnO}_{2}$ nanoparticles. In the mean while the peak located at $670 \mathrm{~cm}^{-1}$ of Raman spectrum is very sharp, which relates to the cubical crystal structure of $\mathrm{Zn}: \mathrm{SnO}_{2}$ nanoparticles obtained due to the $\mathrm{A}_{2 \mathrm{u}}$ longitudinal optical phonon vibration mode. The increase in $\mathrm{A}_{2 \mathrm{u}}$ mode peak might be attributed to the incorporation of $\mathrm{Zn}$ ions in the $\mathrm{SnO}_{2}$ lattice which in turns create more oxygen vacancies and trapping centres [25]. 


\subsection{Chemical analysis}

One of the important method to confirm the elemental, chemical composition and purity of the flame synthesised $\mathrm{SnO}_{2}$ and $\mathrm{Zn}: \mathrm{SnO}_{2}$ nanoparticles is the Energy Dispersive X-ray Analysis (EDX). From fig.4 (a), the EDX spectrum of $\mathrm{SnO}_{2}$ reveals the characteristic peaks of tin at 3 and $3.4 \mathrm{eV}$ and for Oxygen at $0.5 \mathrm{eV}$. Similarly, from fig.4 (b) the EDX spectrum of $\mathrm{Zn}: \mathrm{SnO}_{2}$ reveals the presence of peaks representing to tin at $3.4 \mathrm{eV}$, Oxygen at $0.5 \mathrm{eV}$ and Zinc at 1, 8.6 and $9.6 \mathrm{eV}$. These spectra confirms the purity of the synthesized nanoparticles without any other impurities, which is one of the main advantage of the flame synthesis method. From the fig. 4(b) it can be observed that the intensity of the Sn peak is reduced due to the replacement of $\mathrm{Sn}$ ions by $\mathrm{Zn}$ ions. When $\mathrm{Zn}$ is doped there arises three characteristic peaks representing the presence of zinc in the $\mathrm{SnO}_{2}$ lattice $[9,19]$. Table (1) and (2) shows the weight and atomic percentages of elements that are present in both the synthesized nanomaterials. From the tables it was clear that the oxygen and $\mathrm{Sn}$ percentage was considerably decreased due to the addition of $\mathrm{Zn}$ dopant.

Table 1: EDX data's of pure $\mathrm{SnO}_{2}$ nanoparticles

\begin{tabular}{|c|c|c|c|}
\hline Element & Series & Weight \% & Atomic \% \\
\hline $\mathrm{O}$ & $\mathrm{K}$ & 30.36 & 76.38 \\
\hline $\mathrm{Sn}$ & $\mathrm{L}$ & 69.64 & 23.62 \\
\hline
\end{tabular}

Table 2: EDX datas of $\mathrm{Zn}: \mathrm{SnO}_{2}$ nanoparticles

\begin{tabular}{|c|c|c|c|}
\hline Element & Series & Weight \% & Atomic \% \\
\hline $\mathrm{O}$ & $\mathrm{K}$ & 27.85 & 70.88 \\
\hline $\mathrm{Zn}$ & $\mathrm{L}$ & 15.57 & 9.70 \\
\hline $\mathrm{Sn}$ & $\mathrm{L}$ & 56.58 & 19.42 \\
\hline
\end{tabular}

\subsection{Optical studies}

UV Visible absorption spectroscopy is the most effective way to analyze the various optical properties of the flame synthesized nanoparticles. Fig.5 (a) shows the absorbance versus wavelength peaks for pure $\mathrm{SnO}_{2}$ and $\mathrm{Zn}: \mathrm{SnO}_{2}$ nanoparticles. Both $\mathrm{SnO}_{2}$ and $\mathrm{Zn}: \mathrm{SnO}_{2}$ shows very high absorbance around $300 \mathrm{~nm}$ range and low absorbance above $400 \mathrm{~nm}$.

From these peaks, absorbance edge is red shifted when $\mathrm{Zn}$ doped with $\mathrm{SnO}_{2}$ due to the transfer of electrons from $\mathrm{O}^{-} 2 \mathrm{p}$ states of valence band to $\mathrm{Sn} 3 \mathrm{~d}$ states of conduction band. The band gap values of the synthesized nanoparticles were found using the Tauc plot method,

$$
(\alpha h v)^{2}=\mathrm{A}\left(\mathrm{h} v-\mathrm{E}_{\mathrm{g}}\right)
$$

Where, $\alpha$ is the absorption coefficient, $h v$ is the energy of photon, $\mathrm{A}$ is a constant and $\mathrm{E}_{\mathrm{g}}$ is the band gap energy. Fig. 5(b) shows the Tauc plot graph for both $\mathrm{SnO}_{2}$ and $\mathrm{Zn}: \mathrm{SnO}_{2}$ nanoparticles and using the extrapolation line at the linear region the band gap values are determined as $3.5 \mathrm{eV}$ and $3.4 \mathrm{eV}$ for $\mathrm{SnO}_{2}$ and $\mathrm{Zn}: \mathrm{SnO}_{2}$ respectively. There is an increase in the band gap value which can be explained by the Burstein-Moss broadening effect caused by the addition of $\mathrm{Zn}$ dopant ions in the $\mathrm{SnO}_{2}$ lattice. Due to the $\mathrm{Zn}$ doping there creates new 
electron-hole pairs which in turns create new energy levels in the valence band and conduction band. The increase in band gap and corresponding shift is due to the strong quantum confinement effect of the $\mathrm{Zn}$ dopant [18, 19, 22, 24].

\subsection{Photoluminescence (PL) studies}

In order to find any defects or vacancies that are present in the flame synthesized nanoparticles, photoluminescence is one of the best method. Fig.6 (a) shows the PL emission spectra of pure $\mathrm{SnO}_{2}$ and $\mathrm{Zn}: \mathrm{SnO}_{2}$ nanoparticles, which are excited at $340 \mathrm{~nm}$ and $410 \mathrm{~nm}$ respectively. Due to the electron-hole recombination process the PL peaks arises. $\mathrm{SnO}_{2}$ shows high intensity blue emission peaks at $373.5 \mathrm{~nm}$ and low intensity red emission peak at 549 $\mathrm{nm}$ due to the presence of oxygen vacancy which are created because of the inhibition of electron-hole recombination. Whereas, $\mathrm{Zn}: \mathrm{SnO}_{2}$ shows two low intensity red emission peaks at $582.5 \mathrm{~nm}$ and $687 \mathrm{~nm}$. Due to the doping of $\mathrm{Zn}$ ions in the $\mathrm{SnO}_{2}$ lattice there arises new electron-hole pairs which creates many oxygen vacancy sites [19, 22].

Fig. 6(b) is the CIE (1931) Chromaticity diagram of pure $\mathrm{SnO}_{2}$ and $\mathrm{Zn}: \mathrm{SnO}_{2}$ nanoparticles. From the chromaticity diagram the coordinates for $\mathrm{SnO}_{2}$ was calculated and found as $\mathrm{x}=0.29093$ and $\mathrm{y}=0.33514$, which lies in the blue region [32]. When $\mathrm{Zn}$ doped with $\mathrm{SnO}_{2}$ the coordinates changed to $\mathrm{x}=0.21049$ and $\mathrm{y}=0.14863$, which lies in the violet region. The straight line in the fig.6 (b) indicates the change of coordinates and the color location of the $\mathrm{SnO}_{2}$ and $\mathrm{Zn}: \mathrm{SnO}_{2}$.

\subsection{Surface analysis}

Field Emission Scanning Electron Microscopy (FESEM) is the apt characterization method to analyse the surface morphology and crystalline nature of $\mathrm{SnO}_{2}$ and $\mathrm{Zn}: \mathrm{SnO}_{2}$ nanoparticles. Fig. 7 (a) and (b) are the FESEM images of flame synthesized pure $\mathrm{SnO}_{2}$ and $\mathrm{Zn}: \mathrm{SnO}_{2}$ nanoparticles. During the synthesis of $\mathrm{SnO}_{2}$ nanoparticles, when the bulk metal Sn powders falls on the oxy-acetylene flame, due to the very high temperature of the flame Sn immediately melts and reacts with oxygen to form irregular, agglomerated, nanoflowered and nanoclustered $\mathrm{SnO}_{2}$ nanoparticles. When the $\mathrm{Zn}$ is doped the surface morphology of $\mathrm{SnO}_{2}$ changes drastically to nanocubes and nanoflakes of much improved crystalline structures. FESEM images clearly shows the change in morphology and crystalline nature of the nanoparticles. Due to the doping effect of $\mathrm{Zn}$, there creates new structure formation and enhanced crystalline nature $[20,25]$.

\subsection{Photocatalytic Degradation of MB}

Fig.8 (a) and (b) shows the absorbance spectra of MB in the presence of synthesized photocatalysts under ultraviolet irradiation. Due to the degradation of MB dye, around 661 $\mathrm{nm}$ range the absorption intensity decreases linearly with the increase of irradiation time from 0-180 min. It was also noted that the color of the aqueous solution gradually diminishes as the time of uv irradiation increases [16]. Fig.8(a) shows the MB dye degradation in the presence of $\mathrm{SnO}_{2}$ nanoparticles, before irradiating the $\mathrm{MB}$ solution it was tested without any catalyst(blank test) and with the catalyst in dark which exhibits very low photolysis [2]. When the uv radiations falls on the surface of $\mathrm{SnO}_{2}$, it absorbs the radiation and induce electrons from the lower energy level (valence band) to the higher energy level (conduction band) which results in the formation of highly reactive hydroxyl $\left(\mathrm{OH}^{-}\right)$radicals and superoxide radicals $\left(\mathrm{O}^{2-}\right)$ [16]. Both these radicals plays a vital role in the degradation of $\mathrm{MB}$ dye solution. 
At the end of 180 min uv irradiation, the degradation efficiency of MB dye in the presence of $\mathrm{SnO}_{2}$ catalyst reaches $82 \%$, which can be revealed from the decolorization of the MB solution. Similarly, from fig.8 (b) the photocatalytic degradation efficiency of the aqueous $\mathrm{MB}$ dye solution in the presence of $\mathrm{Zn}: \mathrm{SnO}_{2}$ catalyst was found as $88 \%$. It is evident from the fig.8 (a \& b), $\mathrm{Zn}: \mathrm{SnO}_{2}$ exhibited more photocatalytic degradation activities than pure $\mathrm{SnO}_{2}$.

Kinetic plot for the MB degradation was shown in the fig. 9, which indicates the total degradation process follows a pseudo-first order reaction and the rate constant values were calculated as 0.9555 and 0.9383 for both the nanoparticles. Fig. 10 represents the graph plotted between $\mathrm{C}_{t} / \mathrm{C}_{\mathrm{o}}$ versus time, which clearly indicates the degradation of $\mathrm{MB}$ dye by $\mathrm{SnO}_{2}$ and $\mathrm{Zn}: \mathrm{SnO}_{2}$ nano-photocatalysts [2]. Accordingly, increase in surface area and band gap can be the reason for the enhancement of photocatalytic activity of the $\mathrm{Zn}: \mathrm{SnO}_{2}$ catalysts. Inferred from the analysis, under UV irradiation both $\mathrm{SnO}_{2}$ and $\mathrm{Zn}: \mathrm{SnO}_{2}$ shows higher catalytic activity due to the following reasons: (i) generation of more electron-hole pairs, (ii) transfer of photo generated electrons through the interface from $\mathrm{CB}$ of $\mathrm{SnO}_{2}$ to $\mathrm{CB}$ of $\mathrm{Zn}: \mathrm{SnO}_{2}$ and (iii) transfer of photo-generated holes from $\mathrm{VB}$ of $\mathrm{Zn}: \mathrm{SnO}_{2}$ to $\mathrm{VB}$ of $\mathrm{SnO}_{2}$ which results to the decrease of recombination between the photo-generated holes and electrons [4]. Moreover the electron-hole recombination was reduced due to the presence of $\mathrm{Zn}$ ions that are present in the $\mathrm{Zn}: \mathrm{SnO}_{2}$ catalyst acts as electron traps and increase the formation of superoxide radicals [2]. These radicals induce the direct chemical reaction between the photocatalyst and the dye, which enhance the degradation of MB solution. Moreover, the increase in the photocatalytic degradation activity of both the $\mathrm{SnO}_{2}$ and $\mathrm{Zn}: \mathrm{SnO}_{2}$ photocatalysts are due to the increase of interfacial charge transfer to the substrates and the prolonged life time of the charge carriers by the efficient charge separation process [4].

\section{Conclusions}

Pure $\mathrm{SnO}_{2}$ and $\mathrm{Zn}: \mathrm{SnO}_{2}$ nanoparticles were successfully synthesized by flame synthesis method using the high temperature oxy-acetylene flame. Formation of tetragonal structured pure $\mathrm{SnO}_{2}$ and cubical phased $\mathrm{Zn}: \mathrm{SnO}_{2}$ nanoparticles were confirmed from the XRD analysis. Due to the doping of $\mathrm{Zn}$ in $\mathrm{SnO}_{2}$ lattice the average crystalline size of the nanoparticles is slightly increased from $29 \mathrm{~nm}$ to $30 \mathrm{~nm}$. Raman spectroscopy reveals the oxygen deficiency and the structural changes of the nanoparticles from the vibrational mode analysis. From the EDX analysis, atomic weight percentage and chemical composition confirms the purity of $\mathrm{SnO}_{2}$ and $\mathrm{Zn}: \mathrm{SnO}_{2}$ nanoparticles without any other impurities. UV-visible absorption spectra confirms the Burstein-Moss broadening effect when $\mathrm{Zn}$ is doped with $\mathrm{SnO}_{2}$. Increase in band gap value from $3.5 \mathrm{eV}$ to $3.6 \mathrm{eV}$ was clearly evident from the Tauc plot graph. PL studies exhibit the maximum intensity at $373.5 \mathrm{~nm}$ and $549 \mathrm{~nm}$ for pure $\mathrm{SnO}_{2}$ and for $\mathrm{Zn}: \mathrm{SnO}_{2}$ at $582.5 \mathrm{~nm}$ and $687 \mathrm{~nm}$. Red shifted PL peaks of $\mathrm{Zn}: \mathrm{SnO}_{2}$ confirms the presence of oxygen vacancy sites in the $\mathrm{SnO}_{2}$ lattice. The CIE chromaticity diagram clearly indicates the change in coordinates and the color location (region) of $\mathrm{SnO}_{2}$ and $\mathrm{Zn}: \mathrm{SnO}_{2}$. From the FESEM analysis, it is clearly visible that irregular, agglomerated, nanoflowered and nanoclustered $\mathrm{SnO}_{2}$ nanoparticles changes to nanocubical and nanoflaked $\mathrm{Zn}: \mathrm{SnO}_{2}$ nanoparticles with enhanced crystalline structure. $\mathrm{MB}$ degradation analysis shows the high performance of $\mathrm{SnO}_{2}$ and $\mathrm{Zn}: \mathrm{SnO}_{2}$ nanoparticles as photocatalysts under UV light due to the formation of highly reactive $\left(\mathrm{OH}^{-}\right)$hydroxyl radicals and superoxide $\left(\mathrm{O}^{2-}\right)$ radicals. From these inferences, the optical properties of $\mathrm{SnO}_{2}$ can be improvised by $\mathrm{Zn}$ doping and these nanoparticles synthesized through the very rapid and single step flame oxidation process can be referred as 
one of the most promising and competent photocatalysts for high performance photocatalytic devices and other potential applications.

\section{Declarations}

\section{Funding}

Not applicable

\section{Conflicts of interest/Competing interests}

The authors declare that they have no known competing financial interests or personal relationships that could have appeared to influence the work reported in this paper.

\section{Availability of data and material}

Not applicable

\section{Code availability}

Not applicable

\section{Authors' contributions}

All authors contributed to the study conception and application. Material preparation, data collection and analysis were performed by [P. Sivarama Prabhu], [P. Kathirvel], [D. Maruthamani] and [S.D. Gopal Ram]. The first draft of the manuscript was written by [P. Sivarama Prabhu] and all authors commented on previous versions of the manuscript. All authors read and approved the final manuscript.

\section{Ethics approval}

Not applicable

\section{Consent to participate}

Not applicable

\section{Consent for publication}

This manuscript has not been published previously and it is not under consideration for publication elsewhere, its publication is approved by all authors and if accepted, it will not be published elsewhere in the same form, in English or in any other language, including electronically without the written consent of the copyright holder.

\section{References}

[1] Dang Trung Tri Trinh, Duangdao Channei, Auppatham Nakaruk \& Wilawan Khanitchaidecha, New insight into the photocatalytic degradation of organic pollutant over BiVO4/ SiO2/GO nanocomposite, Scientific Reports, 11 (2021) 4620-4631. https://doi.org/10.1038/s41598-021-84323-5

[2] Olga Długosz and Marcin Banach, $\mathrm{ZnO}-\mathrm{SnO} 2-\mathrm{Sn}$ nanocomposite as photocatalyst in ultraviolet and visible light, Applied Nanoscience, (2021)1-13. https://doi.org/10.1007/s13204-021-01788-6

[3] Ruifen Wang, Kaixuan Shi, Dong Huang, Jing Zhang \& Shengli An, Synthesis and degradation kinetics of TiO2/GO composites with highly efficient activity for adsorption and 
photocatalytic degradation of MB, Scientific Reports, 9 (2019) 18744-18752. https://doi.org/10.1038/s41598-019-54320-w

[4] Tiekun Jia, Junwei Zhao, Fang Fu, Zhao Deng, Weimin Wang, Zhengyi Fu, and Fancheng Meng, Synthesis, Characterization, and Photocatalytic Activity of $\mathrm{Zn}$-Doped $\mathrm{SnO}_{2} / \mathrm{Zn}_{2} \mathrm{SnO}_{4}$ Coupled Nanocomposites, International Journal of Photoenergy, Article ID 197824(2014), 1-7. http://dx.doi.org/10.1155/2014/197824

[5] Sai Kumar Tammina, Badal Kumar Mandal and Nalinee Kanth Kadiyala, Photocatalytic degradation of methylene blue dye by nonconventional synthesized $\mathrm{SnO}_{2}$ nanoparticles, Environmental Nanotechnology, Monitoring \& Management 10 (2018) 339-350. https://doi.org/10.1016/j.enmm.2018.07.006

[6] Easwaramoorthi Ramasamy, P. Kathirvel, S. Kumar, Koppoju Suresh, and Ganapathy Veerappan, Rapid and scalable synthesis of crystalline tin oxide nanoparticles with superior photovoltaic properties by flame oxidation, Materials Research Society Communications, Volume 7, Issue 4, December (2017) 862-866. https://doi:10.1557/mrc.2017.97

[7] K Sreekar Reddy, S. Nithiyanantham, G. Geetha, R. Annie Sujatha, S. Mahalakshmi, Study of Structural and Optical Properties of Fe2+ Doped Tin Oxide Nanoparticles, Journal of Materials and Applications 8(1) (2019) 8-12. https://doi.org/10.32732/jma.2019.8.1.8

[8] P.Kathirvel, Direct synthesis and characterization of high quality tin oxide nanopowders by in-flight oxidation of flame, Optoelectronics and Advanced Materials - Rapid Communications, Vol. 14, No. 1-2, January-February (2020) 73-77.

[9] S. Sivakumar and E. Manikandan, Enhanced structural, optical, electrochemical and magnetic behavior on manganese doped tin oxide nanoparticles via chemical precipitation method, Journal of Materials Science: Materials in Electronics, 30, (2019) 7606-7617. https://doi.org/10.1007/s10854-019-01076-8 [10] Sen Liu, Ziying Wang, Yong Zhang, Chunbo Zhang and Tong Zhang, High performance room temperature $\mathrm{NO} 2$ sensors based on reduced graphene oxide-multiwalled carbon nanotubes-tin oxide nanoparticles hybrids, Sensors and Actuators B 211 (2015) 318-324. http://dx.doi.org/10.1016/j.snb.2015.01.127

[11] K. Vijayarangamuthu and Shyama Rath, Nanoparticle size, oxidation state, and sensing response of tin oxide nanopowders using Raman spectroscopy, Journal of Alloys and Compounds 610 (2014) 706-712. http://dx.doi.org/10.1016/j.jallcom.2014.04.187

[12] Sen Liu, Ziying Wang, Yong Zhang, Jiacheng Li and Tong Zhang, Sulfonated graphene anchored with tin oxide nanoparticles for detection of nitrogen dioxide at room temperature with enhanced sensing performances, Sensors and Actuators B 228 (2016) 134-143. http://dx.doi.org/10.1016/j.snb.2016.01.023

[13] L.I.Nadaf and K.S.Venkatesh, Synthesis and Characterization of Tin Oxide Nanoparticles by Co-precipitation Method, IOSR Journal of Applied Chemistry, Volume 9, Issue 2 Ver. I (2016) 01-04. https://doi: 10.9790/5736-09210104

[14] T.Krishnakumar, R. Jayaprakash, V.N. Singh, B.R. Mehta, and A. R. Phani, Synthesis and characterization of tin oxide nanoparticle for humidity sensor applications, Journal of Nano Research Vol. 4 (2008) 91-101.https://doi:10.4028/www.scientific.net/JNanoR.4.91 [15] Weijun Ke, Guojia Fang, Qin Liu, Liangbin Xiong, Pingli Qin, Hong Tao, Jing Wang, Hongwei Lei, Borui Li, Jiawei Wan, Guang Yang and Yanfa Yan, Low-Temperature Solution-Processed Tin Oxide as an Alternative Electron Transporting Layer for Efficient Perovskite Solar Cells, Journal of American Chemical Society, 137 (2015) 6730-6733. https://doi: 10.1021/jacs.5b01994

[16] M. Parthibavarman, S. Sathishkumar and S. Prabhakaran, Enhanced visible light photocatalytic activity of tin oxide nanoparticles synthesized by different microwave 
optimum conditions, Journal of Materials Science: Materials in Electronics, 29(3),February (2018) 2341-2350. https://doi: 10.1007/s10854-017-8152-3

[17] Suresh Sagadevan, Mohd. Rafie Bin Johan, Fauziah Abdul Aziz, Hsiu-Ling Hsu, Rosilda Selvin, H. H. Hegazy, Ahmad Umar, H. Algarni, and L. Selva Roselin, Influence of Mn Doping on the Properties of Tin Oxide Nanoparticles Prepared by Co-Precipitation Method, Journal of Nanoelectronics and Optoelectronics, Vol. 14, (2019) 1-10. https://doi:10.1166/jno.2019.2588

[18] Boya Venugopal, Brajesh Nandan, Amutha Ayyachamy, Venkatesan Balaji, Sankarakumar Amirthapandian, Binaya Kumar Panigrahi and Thangadurai Paramasivam, Influence of manganese ions in the band gap of tin oxide nanoparticles: structure, microstructure and optical studies, RSC Advances, 4 (2014) 6141-6150. https://doi:10.1039/c3ra46378h

[19] Riddhiman Medhi, Chien-Hung Li, Sang Ho Lee, Maria D. Marquez, Allan J. Jacobson, Tai-Chou Lee and T. Randall Lee, Uniformly Spherical and Monodisperse Antimony- and Zinc-Doped Tin Oxide Nanoparticles for Optical and Electronic Applications, ACS Applied Nano Materials, 2 (2019) 6554-6564. https://doi: 10.1021/acsanm.9b01474

[20] Qinqin Zhao, Lisha Ma, Qiang Zhang, Chenggang Wang, and Xijin Xu, SnO2-Based Nanomaterials: Synthesis and Application in Lithium-Ion Batteries and Supercapacitors, Journal of Nanomaterials, Article ID 850147, (2015) 1-15. http://dx.doi.org/10.1155/2015/850147

[21] Abdullah M. Al-Hamdi, Mika Sillanpää, and Joydeep Dutta, Photocatalytic degradation of phenol by iodine doped tin oxide nanoparticles under UV and sunlight irradiation, Journal of Alloys and Compounds, $618 \quad$ (2015) 366-371. http://dx.doi.org/10.1016/j.jallcom.2014.08.120

[22] K. Sakthiraj, B.Karthikeyan and K. Balachandrakumar, Structural, Optical and Magnetic properties of Copper $(\mathrm{Cu})$ doped Tin oxide $(\mathrm{SnO} 2)$ nanocrystal, International Journal of ChemTech Research, Vol.7, 3 (2015) 1481-1487.

[23] Simin Tazikeh, Amir Akbari, Amin Talebi and Emad Talebi, Synthesis and characterization of tin oxide nanoparticles via the Co-precipitation method, Materials Science-Poland, 32(1), (2014) 98-101. http://doi: 10.2478/s13536-013-0164-y.

[24] Suresh Sagadevan and Jiban Podder, Investigation on Structural, Surface Morphological and Dielectric Properties of $\mathrm{Zn}$-doped $\mathrm{SnO}_{2}$ Nanoparticles, Materials Research, 19(2), March (2016) 420-425. http://dx.doi.org/10.1590/1980-5373-MR-2015-0657

[25] Virender Kumar, Kulwinder Singh, Jeewan Sharma, Akshay Kumar, Ankush Vij and Anup Thakur, Zn-doped SnO2 nanostructures: structural, morphological and spectroscopic properties, Journal of Materials Science: Materials in Electronics, 28(24) (2017) 1884918856. http://doi: 10.1007/s10854-017-7836-Z

[26] R. Bargougui, A. Oueslati, G. Schmerber, C. Ulhaq-Bouillet, S. Colis, F. Hlel, S. Ammar and A. Dinia, Structural, optical and electrical properties of Zn-doped SnO2 nanoparticles synthesized by the co-precipitation technique, Journal of Materials Science: 25 : (2014) 2066-2071. http://doi: 10.1007/s10854-014-1841-2

[27] Zhiyang Chen, Yuan Zhu, Qiyao Duan, Anqi Chen, Zikang Tang, Spray-combustion synthesis of indium tin oxide nanopowder, Journal of the American Ceramic Society, 102 (2019) 42-47. http://doi: 10.1111/jace.15957

[28] M. Zaccaria, D. Fabiani, G. Cannucciari, C. Gualandi, M. L. Focarete, C. Arbizzani, F. De Giorgio and M. Mastragostino, Effect of Silica and Tin Oxide Nanoparticles on Properties of Nanofibrous Electrospun Separators, Journal of The Electrochemical Society, 162 (6) (2015) A915-A920. http://doi: 10.1149/2.0421506jes 
[29] Ho Yun Lee, Im Jeong Yang, Jang-Hee Yoon, Sung-Ho Jin, Seohan Kim and Pung Keun Song, Thermoelectric Properties of Zinc-Doped Indium Tin Oxide Thin Films Prepared Using the Magnetron Co-Sputtering Method, Coatings, 9, 788 (2019) 1-10. http://doi:10.3390/coatings9120788

[30] Florian Dumitrache, Iuliana P. Morjan, Elena Dutu, Ion Morjan, Claudiu Teodor Fleaca, Monica Scarisoreanu, Alina Ilie, Marius Dumitru, Cristian Mihailescu, Adriana Smarandache and Gabriel Prodan, Zn/F-doped tin oxide nanoparticles synthesized by laser pyrolysis: structural and optical properties, Beilstein Journal of Nanotechnology, 10, (2019) 9-21. https://doi:10.3762/bjnano.10.2

[31] Mehar Bhatnagar, Vishakha Kaushik, Akshey Kaushal, Mandeep Singh, and Bodh Raj Mehta, Structural and photoluminescence properties of tin oxide and tin oxide: C core- shell and alloy nanoparticles synthesized using gas phase technique, AIP Advances, 6(9) 095321 (2016) 1-11. https://doi.org/10.1063/1.4964313

[32] K. Lakshmi, SK. Shahenoor Basha and M.C. Rao, Optical and Photoluminescent Studies on Vo2+ doped Sno2 Thin Films, Rasayan Journal of Chemistry, 10(2), (2017) 682-688. http://dx.doi.org/10.7324/RJC.2017.1021744

[33] T. Raguram and K. S. Rajni, Synthesis and analysing the structural, optical, morphological, photocatalytic and magnetic properties of $\mathrm{TiO}_{2}$ and doped $(\mathrm{Ni}$ and $\mathrm{Cu}) \mathrm{TiO}_{2}$ nanoparticles by sol-gel technique, Applied Physics A, 125:288 (2019) 1-11. https://doi.org/10.1007/s00339-019-2581-1 
Figures

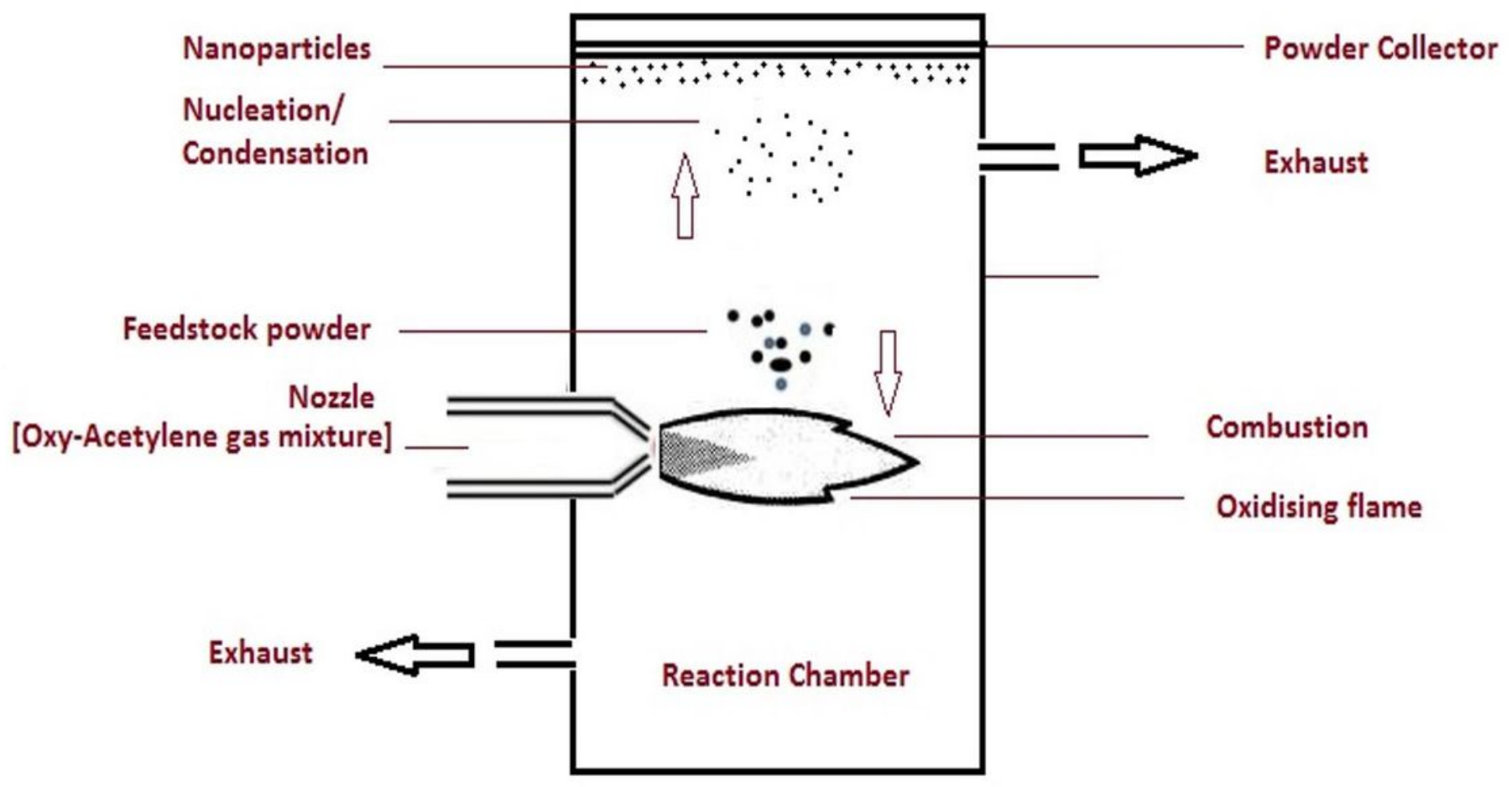

Figure 1

Schematic diagram of Flame synthesis method 


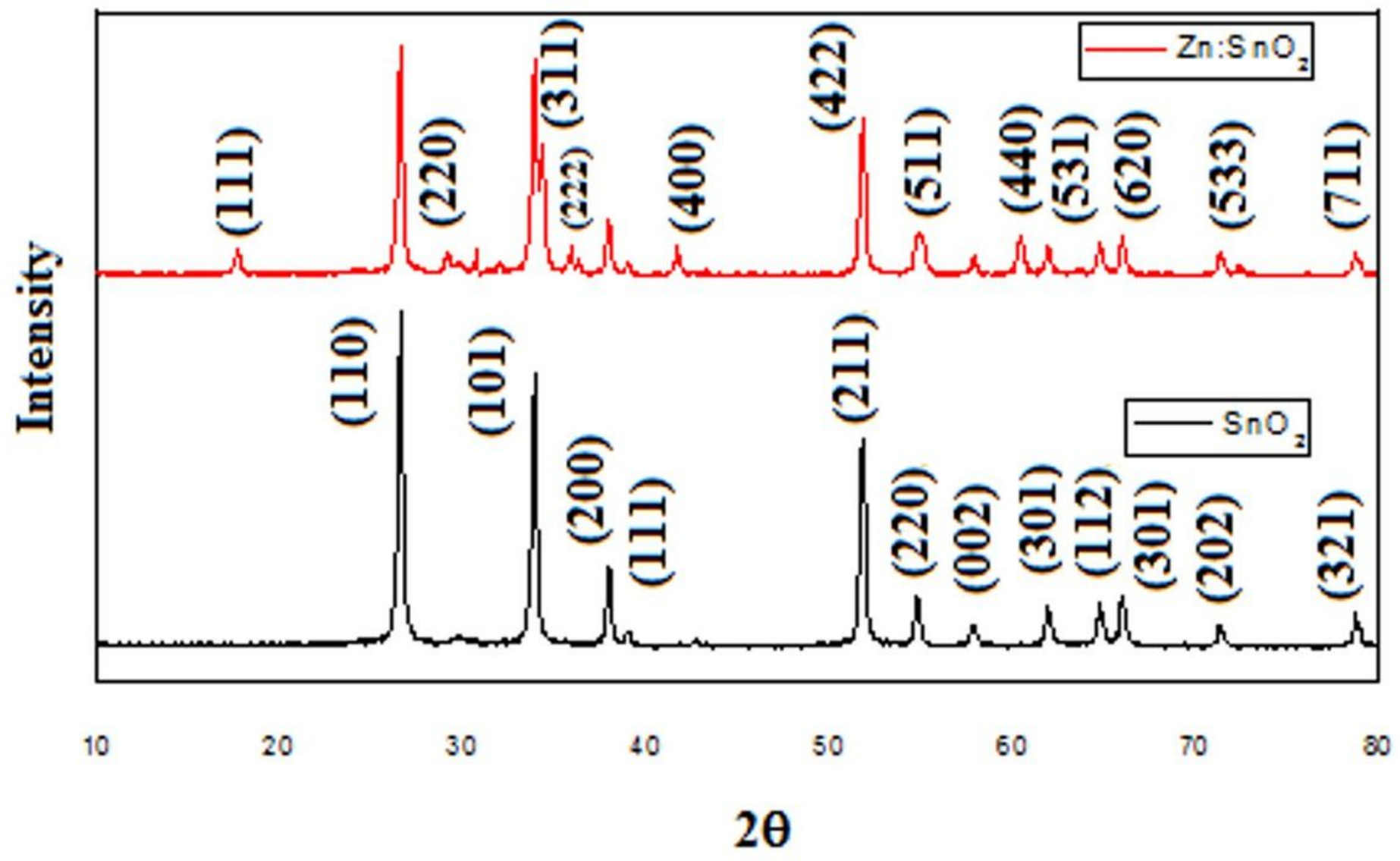

Figure 2

Xrd of pure SnO2 and Zn:SnO2 nanoparticles 


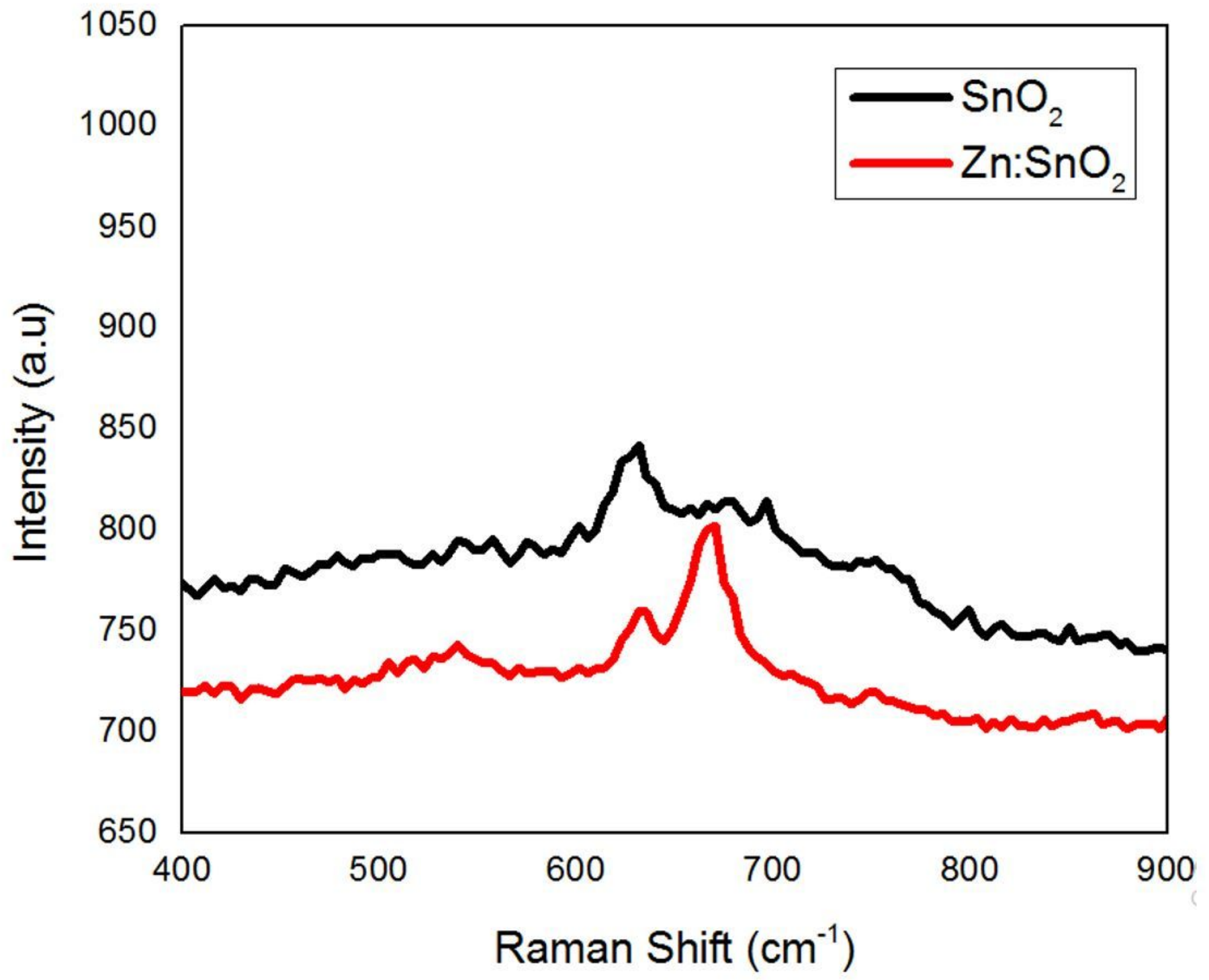

Figure 3

Raman spectra of pure SnO2 and Zn:SnO2 nanoparticles 

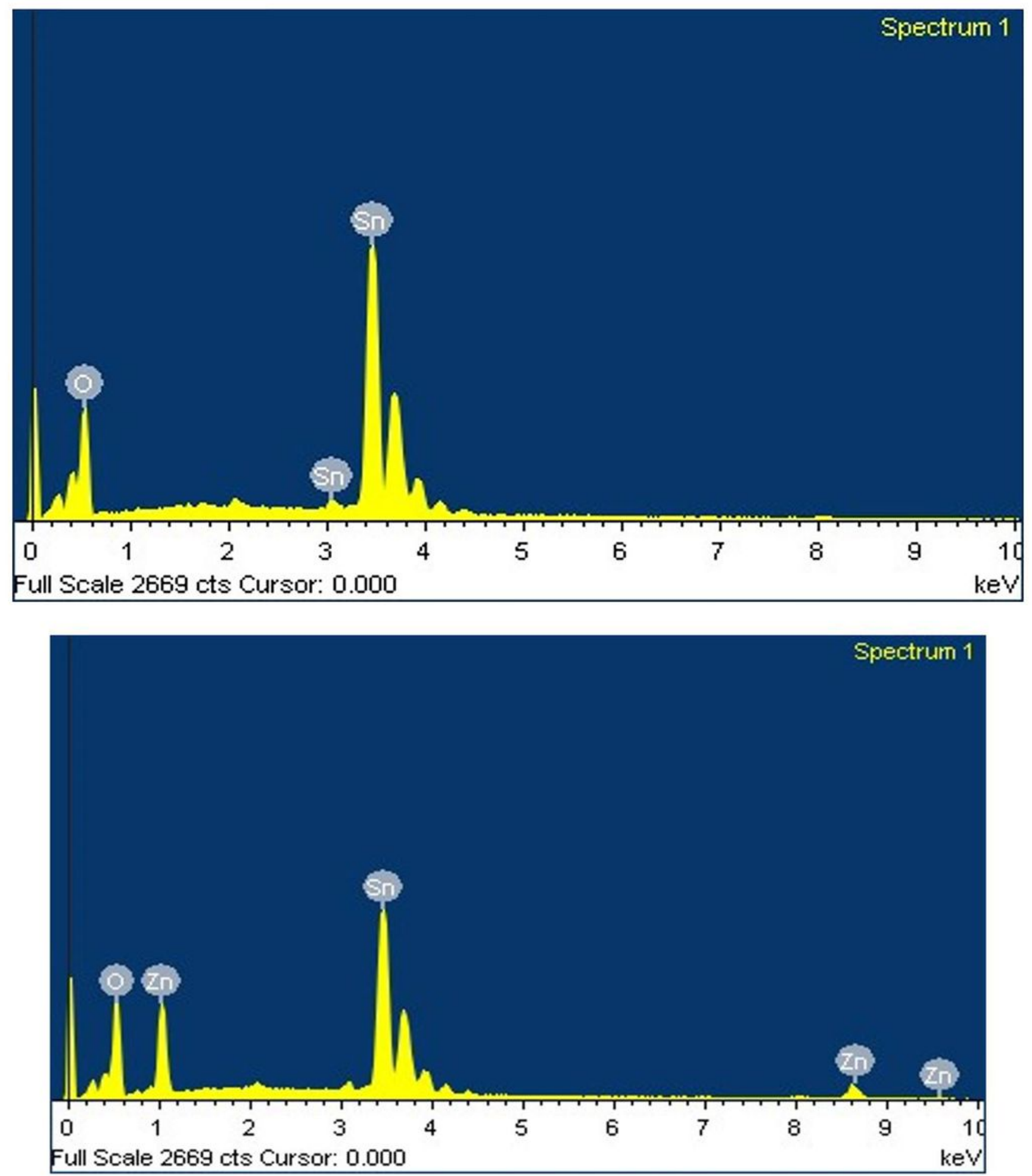

Figure 4

(a) EDX Spectra of pure SnO2 nanoparticles (b) EDX Spectra of Zn:SnO2 nanoparticles 

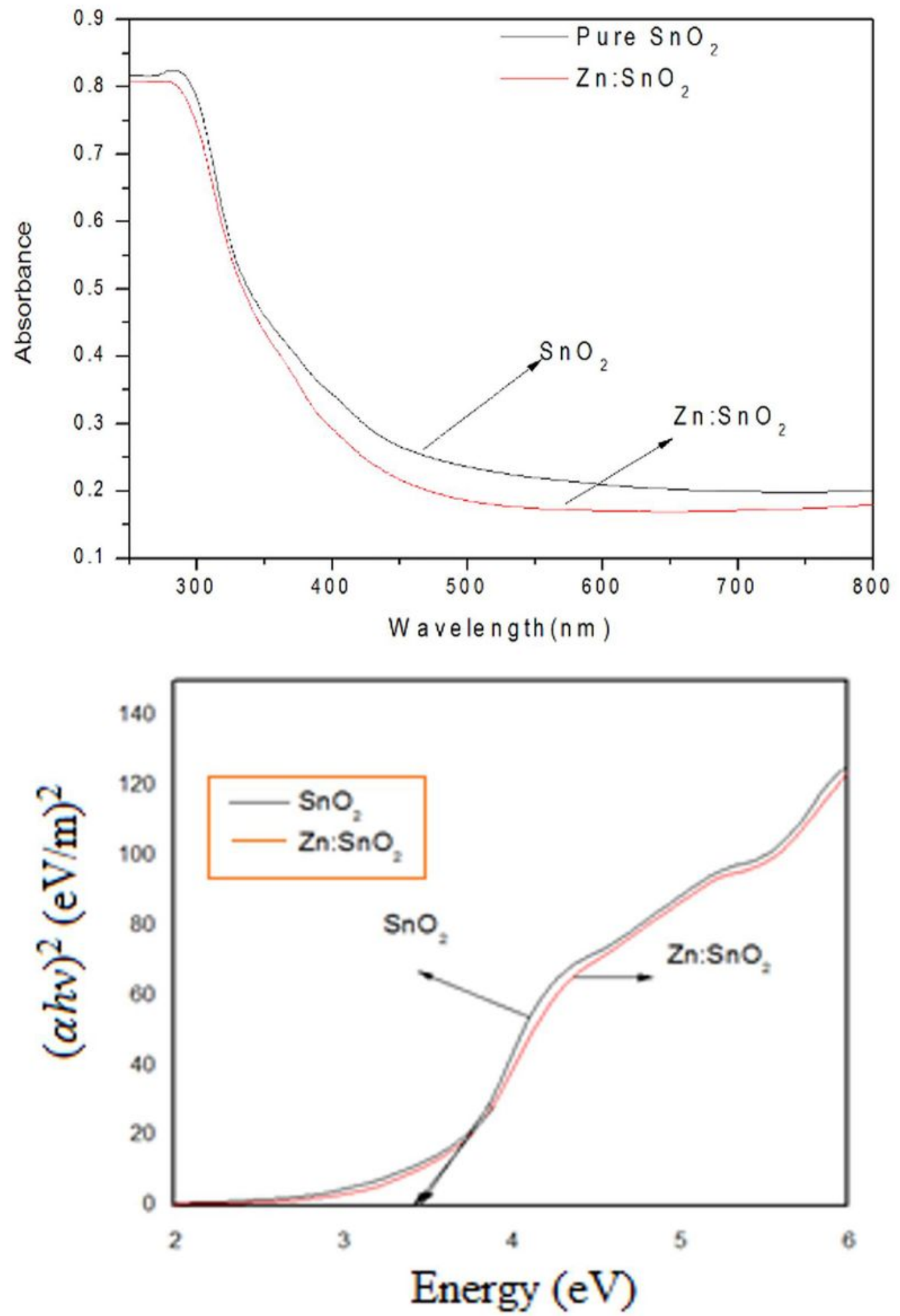

Figure 5

(a) Absorbance spectra of $\mathrm{SnO} 2$ and $\mathrm{Zn}: \mathrm{SnO} 2$ nanoparticles (b) Tauc plot of $\mathrm{SnO} 2$ and $\mathrm{Zn}: \mathrm{SnO} 2$ nanoparticles 


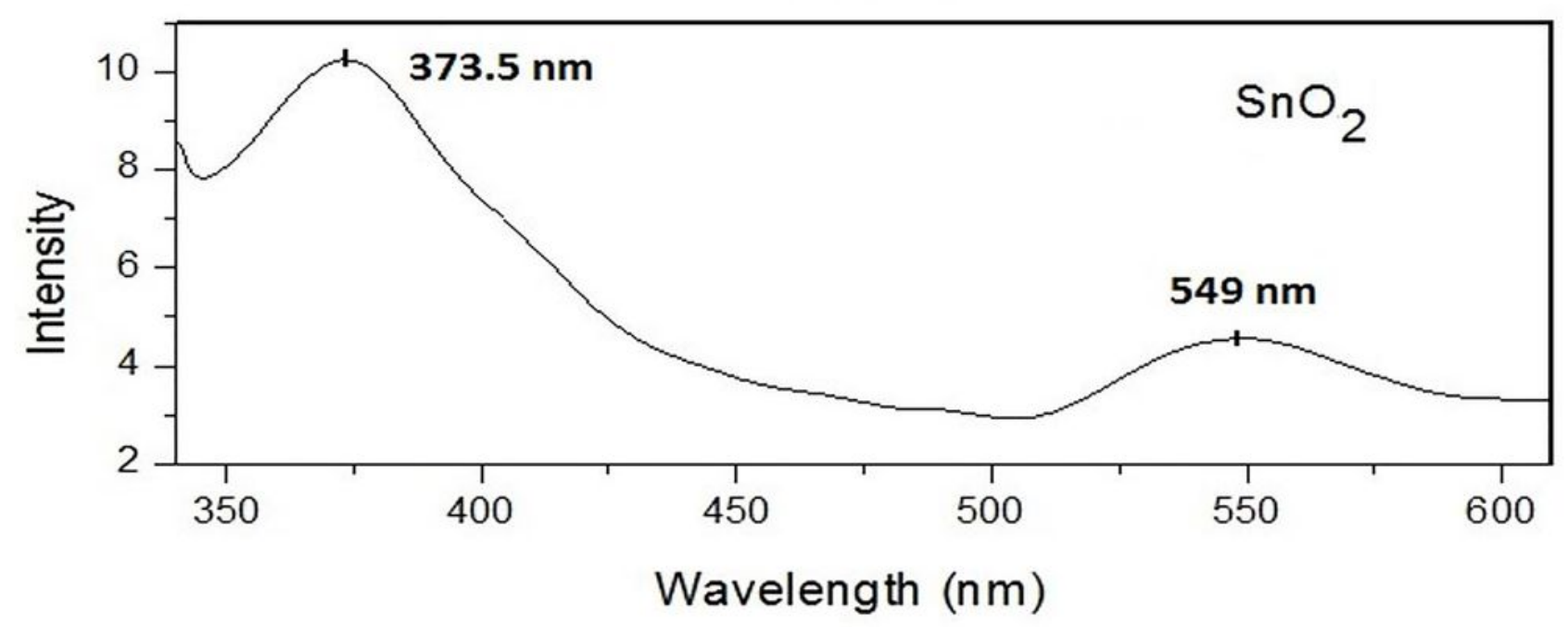

CIE 1931

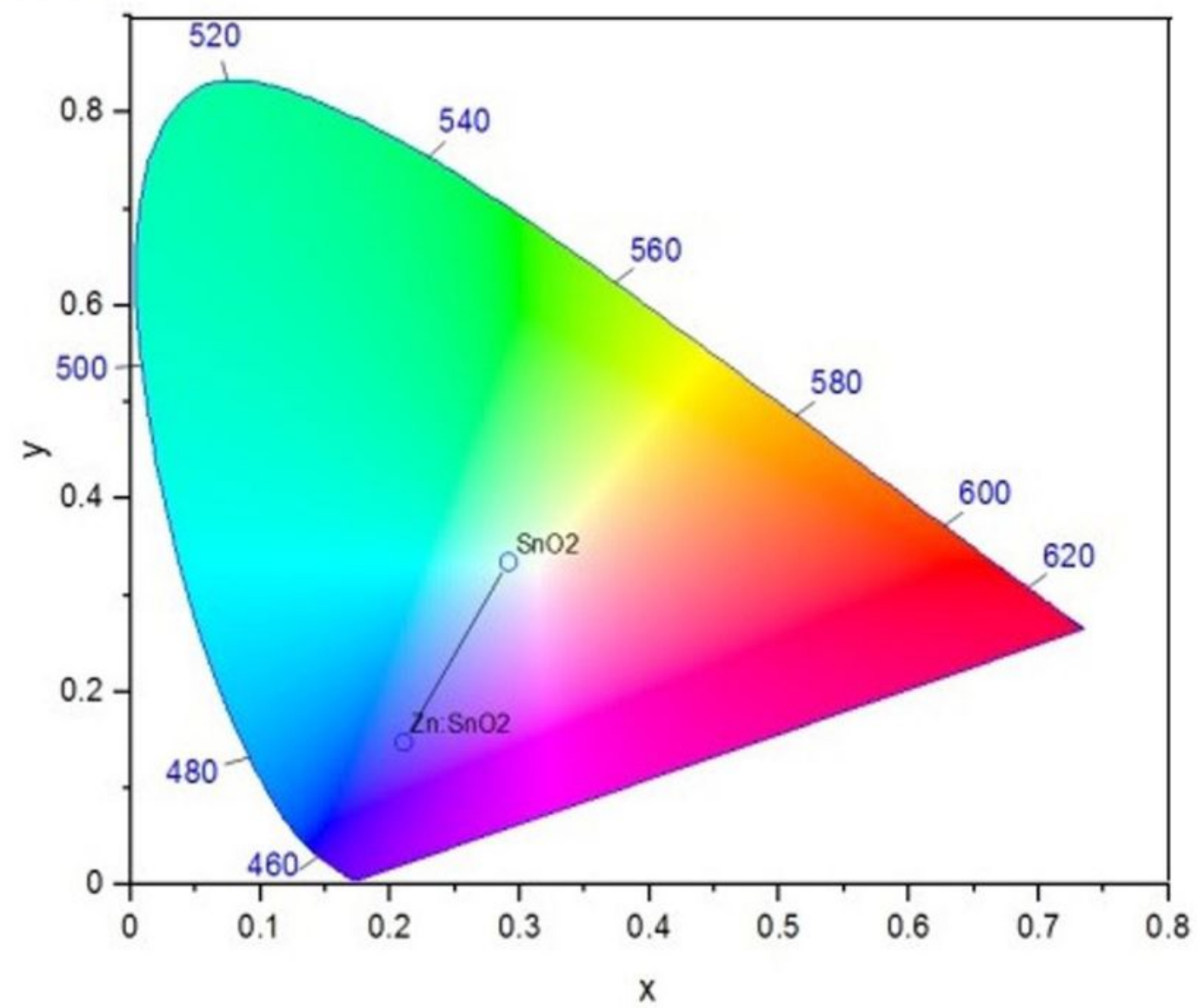

Figure 6

(a) PL spectra of Pure SnO2 and Zn:SnO2 nanoparticles (b) CIE Chromaticity diagram of Pure SnO2 and $\mathrm{Zn:SnO2} \mathrm{nanoparticles}$ 

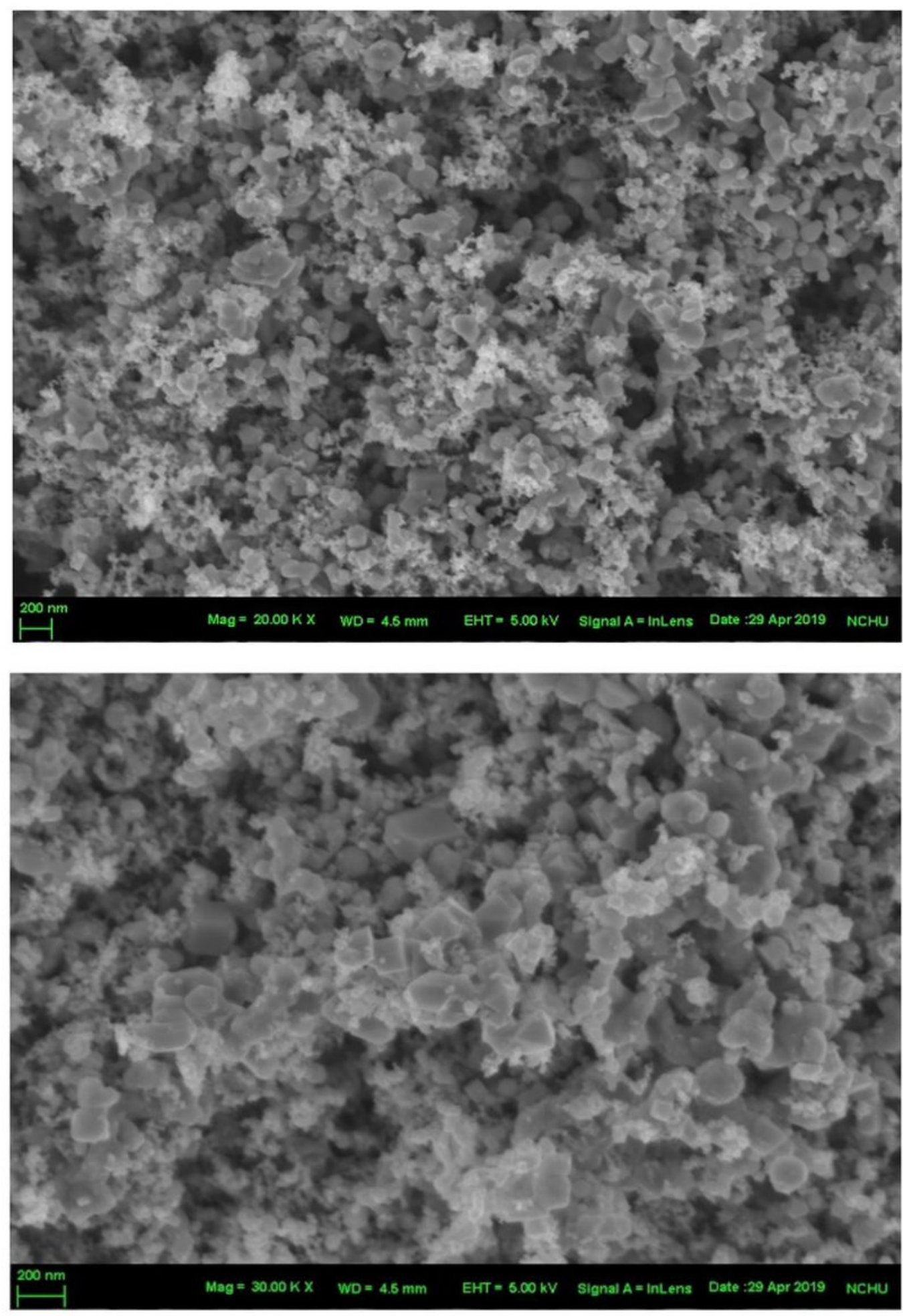

Figure 7

(a) FESEM image of pure SnO2 nanoparticles (b) FESEM image of $\mathrm{Zn:SnO2} \mathrm{nanoparticles}$ 

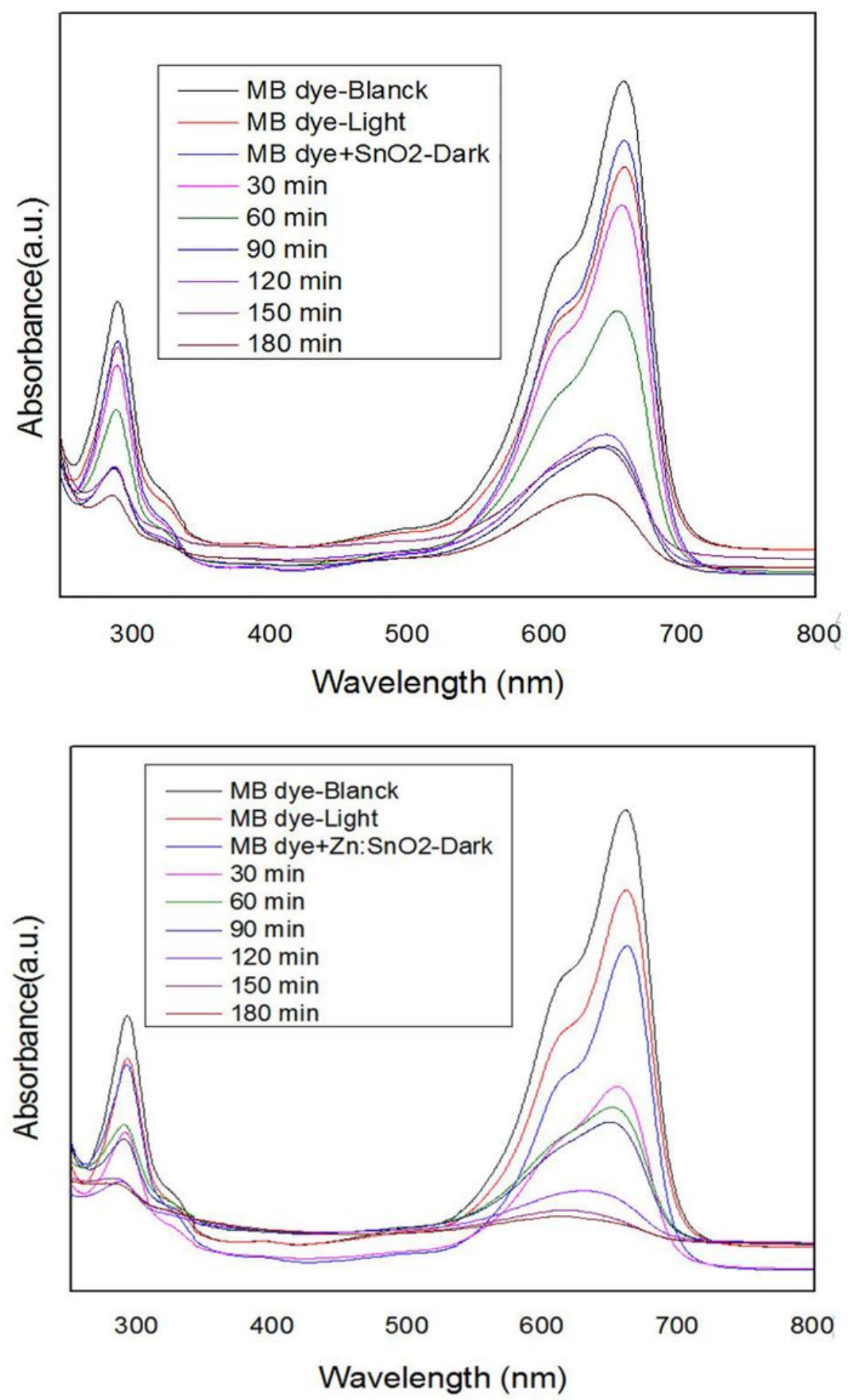

Figure 8

(a) MB degradation in presence of $\mathrm{SnO} 2$ nanoparticles (b) $\mathrm{MB}$ degradation in presence of $\mathrm{Zn}: \mathrm{SnO} 2$ nanoparticles 


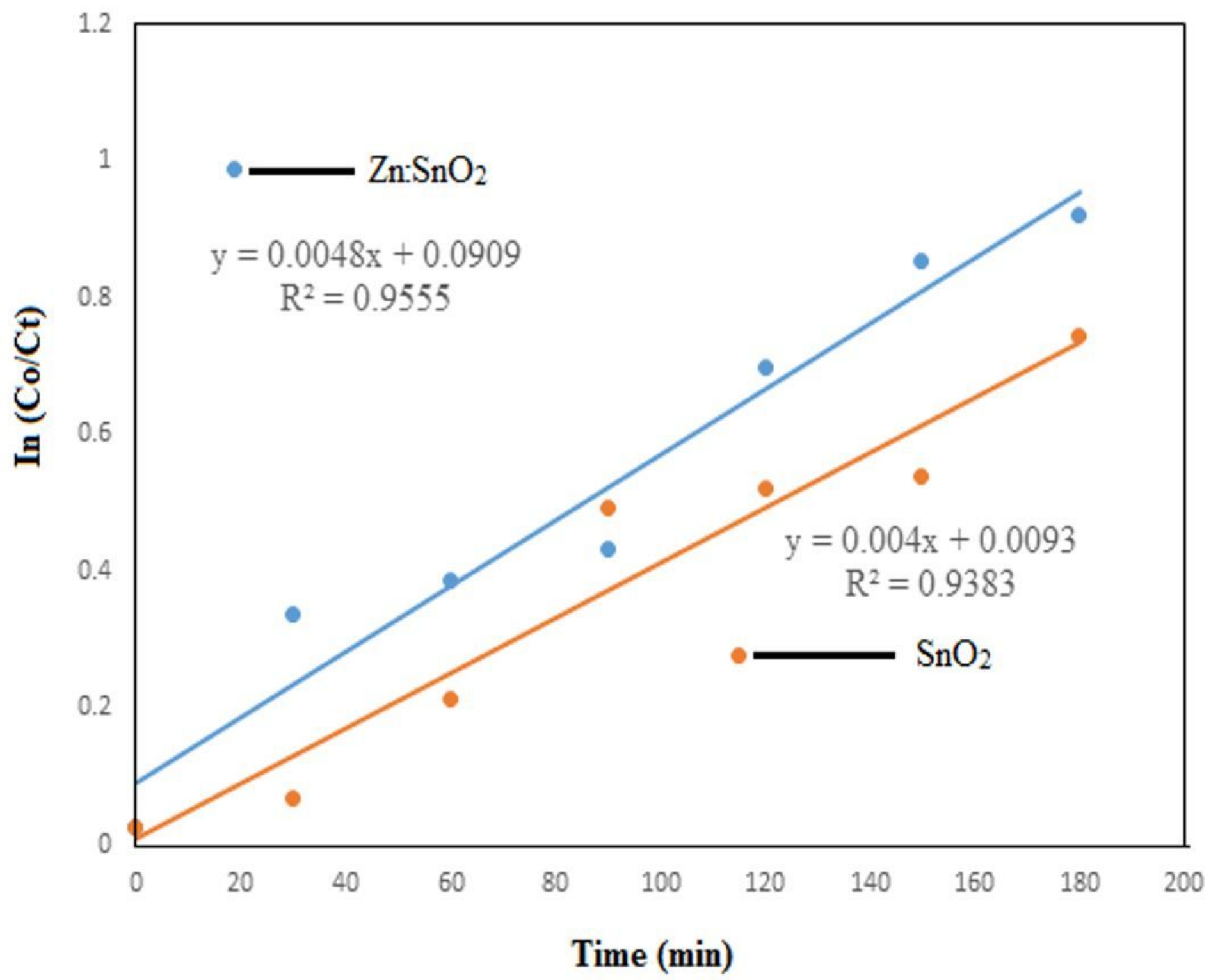

Figure 9

Kinetic plot of MB degradation by $\mathrm{SnO} 2$ and $\mathrm{Zn}: \mathrm{SnO} 2$ nanoparticles 


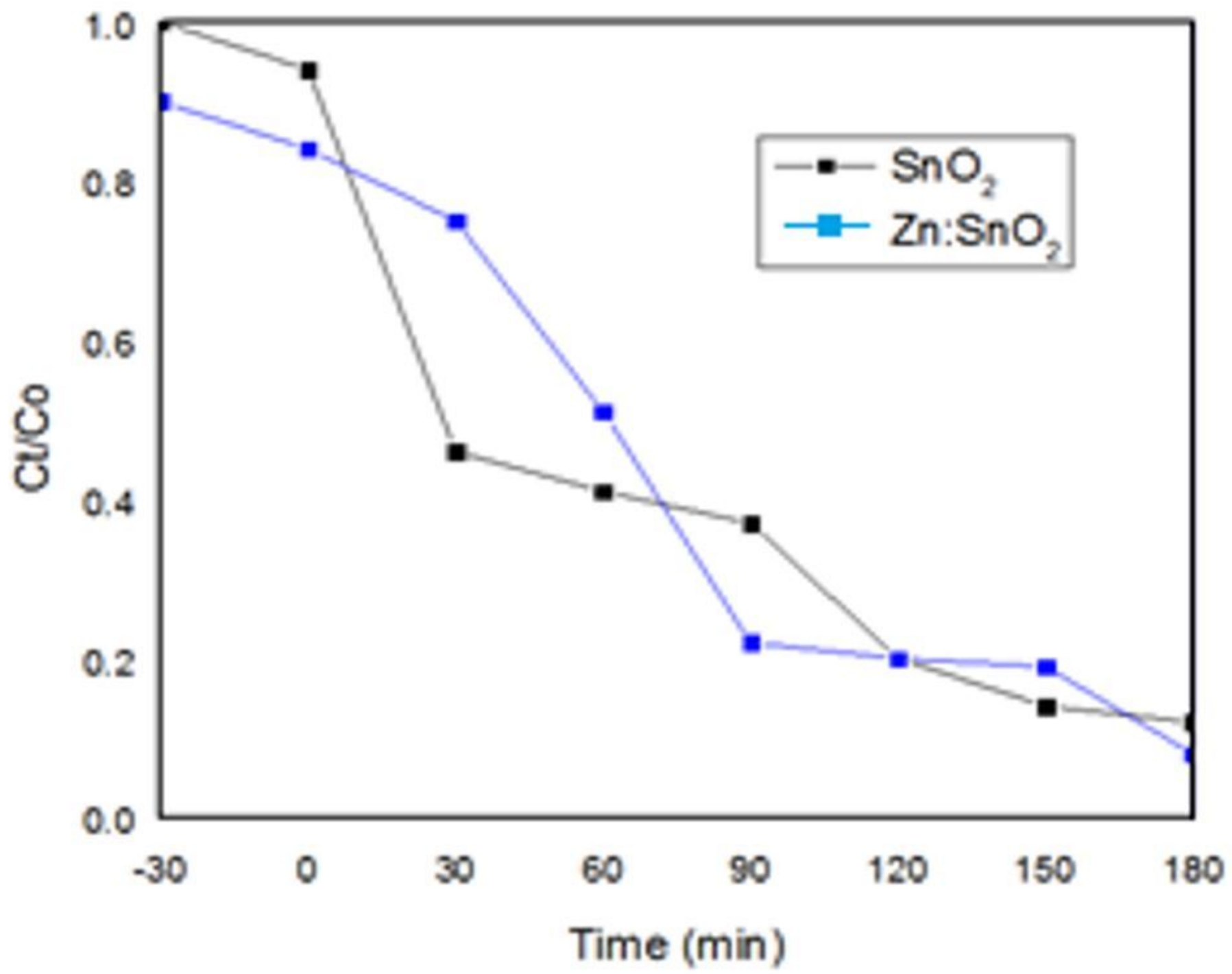

Figure 10

$\mathrm{Ct} / \mathrm{Co}$ versus time graph 